\title{
Study of Humanity Teaching Model in Higher Vocational School Chinese Teaching
}

\author{
Jianfeng $\mathrm{Wu}^{1, \mathrm{a}}$, Yanqin $\mathrm{Yan}^{2, \mathrm{~b}}$ \\ 12 Jiangxi College of Foreign Studies, Nanchang, Jiangxi, 330099 \\ ${ }^{a}$ email, ${ }^{b}$ email
}

Keywords: Humanity Teaching, Higher Vocational School, Teaching Model

\begin{abstract}
Economic development, science and technological advances of the times make a higher requirement for the new technical personnel. Thus, in the new social environment and background, higher vocational colleges not only teach students professional skills and achievements, but also make students have good professionalism, high moral character, etc., it is to nurture students to become adaptation social development and the needs of enterprises with comprehensive quality talent. It is necessary to have the "hard power" and also have "soft connotation." But the vocational students' cultural literacy situation has serious problem, which in addition to social and family factors, lack of humanistic education with vocational school also has a close relationship.
\end{abstract}

\section{Introduction}

Economic development, progress, science and technological advances of the times, the standard applied in the new technical personnel and a higher requirement. Thus, in the new social environment and background functions of higher vocational colleges not only teach students professional skills and achievements, but also to make students have good professionalism, high moral character, etc., it is to nurture students to become adaptation social development and the needs of enterprises with comprehensive quality talent. It is necessary to have the "hard power", but also have "soft connotation." But the vocational students' cultural literacy situation but there is a serious problem, which in addition to social and family factors, lack of humanistic education with vocational school also has a close relationship.

Today's society, filled with advanced technology and productivity, open world in exhibits full of vigor and vitality at the same time, it also contains various contradictions and conflicts. The era of human resources, reform and innovation is the essence of competing technologies, national competition in the final analysis is the talent competition, which gives education nowadays made more specific and challenging requirements of education for the community to take up the cultivation of talents responsibility. Ye said: The purpose of education is to teach students life. This sentence also points to the premises and personnel standards defined, before becoming a service and the benefit of social development "only" First, it should be an independent personality, moral training and cultural connotation of the "people", that is, we often Speaking of, to become, the first adult. So make students adults, should be what kind of education? Undoubtedly the language teaching as a means of education and culture permeate humanistic spirit, and it is very necessary and essential. Chen Tai Asia in "education, make life better," elaborated: "Education is not knowledge transfer of labor, but the spirit of mutual encouragement between people and understanding, so that life mutual appreciation and encouragement, is the proper meaning of education.

\section{Necessity of Humane Education in Vocational Teaching}

Social progress and development in the final analysis is human development. Human development lies in its human development, the development of the fundamental humanity lies in the development of humanistic education. It follows that, in the conduct humanities language teaching in vocational penetration is extremely necessary. The father of modern education points that the human development itself, is the essence and the ultimate goal of education. Successful school 
education is not how much knowledge the students, trained highly skilled, but in the formation of students' personality and literacy, so that they get a sense of happiness from the Humane Education. Education, and shall meet the quiet state of mind of children, so as to develop their inner spirit, to develop an independent personality. The object of education is a human, who had for others and these people are thinking of the essential difference between animal, human and animal, in its social nature. People should be based on the world, we must understand the art of survival and acted philosophy. Have a good humanities, is one reason why the basic human condition. Informative and professional education today, so it ignored as the object of education in the process of education, ignoring the human spirit and soul. Education should be the essence of people's education, that education should be a comprehensive treatment of people who want to become complete human beings, need to be trained and physically multifaceted human development should be comprehensive, training is extensive. Comenius said: If you want to form a real person, education is the ways and means necessary. The inevitable process of education is closely linked with the acquisition of knowledge, but the ultimate goal of education is not the acquisition of knowledge, but to improve the state of humanity in understanding the spirit and sense of self-decomposition process. Great leader Mao Zedong said: people always have a little spirit. The human spirit should be its heart and soul.

Mr. Qian has long believed and noted that the greatest shortcomings of Chinese language education are "arrogant." Defiant education and more reflects the fitness of the current status of Chinese education. Humanity is missing and making the most cultural characteristics of Chinese subject, but also the transformation of its functions, as a practice and techniques of science, and language symbols purely for the purpose. A chapter of the text in the language teacher consummate skill, the solution is bovine small blister-like pieces, the article itself harmony, natural, structural analysis is also the collapse of everything. A chapter Essay in such a dismemberment to be destroyed completely, no beauty. Schiller had predicted that modern technology once there, it will become a force for alienation has a strong effect, so that the meaning of life and spiritual values whom suffocation. Rousseau that science has brought advanced productive force, it would also devoid of humanity, to suppress the human mind and spiritual growth. It features new Chinese curriculum standard, located in the instrumental and human unity, which is the education sector has a great significance and impact of return. Therefore, only the educated based on humanity itself, education is education, only the educated mind to focus on the healthy growth of education becomes that humanities education. Yu Yi teachers believe that to achieve the comprehensive development of people, it must first "Head someone", which requires education for all students, students should be healthy growth in the first place, "Head someone" is a comprehensive, harmonious development premise. Today's world is beautiful flowers in the world, today's world, but also filled with all kinds of war, terrorism, power politics, the arms race and the like. Economic development, social situation under materialistic, money, power, and sex is full of people's attention, the temptation soul vulnerable people. The so-called squandering For beautiful eyes, vocational school students fascinated in this colorful world, they have no interest nor the patience to pursue a classic literary classics in order to nourish the heart, every day is a clenched hand phone, play the game, they lack the concept of right and wrong, lack of compassion, the heritage of civilization has become urgent problem.

\section{Vocational Humanities Teaching Mode}

Actively promote independence, cooperation and explore ways of learning. Teaching should be for students to create a good self-learning scenario, aimed at the most basic common sense as Humanistic classic, in this atmosphere helps students to develop their consciousness, combined with their own characteristics, needs, to explore their own learning path, deepen understanding of literature, rather than mechanically accept the literary knowledge of history. Cooperative learning is conducive to encourage individuals to actively participate in discussions on the basis of study on tolerance and learn to communicate with each other in the excitation of wisdom, making students' intelligence, the ability to fully develop. 
Prominent university teaching language classes cultural characteristics. (1) collect information, layout preview. Combined with the transmission of knowledge, focus on training students to collect materials and the ability to organize materials; before a new lesson to encourage students access to information sent to preview findings, including the questioning, to enable students to develop the habit of active learning, classroom teaching to ensure a high starting point. (2) conduct seminars. Teachers organize seminars with active students 'thinking, to mobilize the students' interest, so that high school language teaching and distinguished. (3) organize the discussion class, advocated "Qunyan Tang." By co-discrimination, refute, guidance and imperceptibly infected young students to develop their human spirit, enhance their overall quality (critical thinking skills, verbal ability, etc.). Practice has proved that the students are very interested podium to express their views. (4) innovation, the introduction of advanced teaching methods and means. Such as making into a multimedia language lessons into language lab, or even the cinema, into life, to enable students to fully appreciate the language and cultural atmosphere breath of life, which becomes boring, single oral presentation is lively, vibrant bilateral activities.

Diversification of Assessment and Evaluation. The purpose of the evaluation is to promote the improvement of the quality of students' language. Follow the students' ability in practical tasks in question are manifested in the evaluation should be looking for answers capabilities, the ability to understand, ability to cooperate, creative ability, communication skills and the ability to evaluate. Evaluation focused on how to make these students' capacity to develop and improve on, not just how to judge the ability of students. Evaluation should focus on student differences and diversity, breaking the rigid, traditional uniform evaluation mode, so that the evaluation richer results.

Teachers' self-improvement. Faced with higher learning needs of college students, vocational school language teachers must first learn through enhanced continuously improve their literacy. Teachers should make every effort in language teaching to fully demonstrate their qualities, to show their personality, showing the charm of language and literature, so that students love the national culture, to develop good language learning habits, having good language skills, acquire extensive language knowledge. Teachers teaching distinct personality and teaching style show, also marks the flourishing teaching atmosphere is formed. College Chinese as basic course, course content relates to ancient and modern literature, with talk of there ancient Chinese knowledge, literary theory, philosophy, art, and even religion. This requires language teachers to the University "Encyclopedia pass", it is a "hybrid" home, business, though not very special, but Bo, language, literature, culture, history, philosophy, religion, writing and other related knowledge should be understood. Only with a broad range of knowledge to comprehend by analogy, can put the lessons lively, in order to stimulate students' interest in learning. It must also take into account the necessary tools of language courses to students a little more reading, writing and speaking opportunities, but also to pass this course to enable students to learn to appreciate the culture of quality, learn how to enrich their own imagination, sensibility and thinking, improve their verbal skills. So that high-grade reading and writing has become a good habit, so outstanding verbal skills an ability to become lifelong. Such vocational language is not only the basis of extending the language, but also to enhance the basic language of a higher level.

Should not rigidly adhere to existing materials, according to the actual needs of the students professional, flexible adjustment of "College Chinese" teaching content. The actual needs of students from professional point of view, focusing on the culture to stimulate students 'interest and ability; to expand the literature by means of a rich culture, from culture to culture and ultimately achieving students' humanistic spirit and personality. Teaching ideas for clues to the history of Chinese literature, modern and contemporary foreign literature interspersed thematic and cultural topics. In the history of Chinese literature as "line" to writers to "point" to the relevant cultural knowledge "face" to the theme "plate", form the knowledge structure interchange.

\section{Conclusion}

Humanistic Education in Higher Vocational Education is the foundation of education, strengthening humanistic quality education is to achieve overall optimization of education, to teaching, 
management education, service education, environmental education purposes. Therefore, the search for Higher Education Humanities Education Significance and specific embodiment Humanistic Education in Chinese Teaching on practical and double historical significance. This exploration is not only related to the healthy development of vocational basic education, but also concerned with the relationship between the survival and development of vocational education territory.

\section{Acknowledgements}

Project Fund: 2013 College Humanity subject item of Jiangxi Province (JY1347).

\section{References}

[1] Guo Yuying. Vocational language teaching and Humanities Quality Training [J]. Modern Languages .2006 (7).

[2] Hui Juanliu. On the vocational language teaching and Humanities Education [J]. Health Vocational Education. 2007 (23).

[3] Wang Shangwen. Limitations scientism, the Sprit of Humanities [J]. Chinese Learning, 1993 (1).

[4] Yang Changqing. Status of vocational language teaching [J]. Occupation. 2007 (7).

[5] Fu Yiping. On language teaching in vocational Strengthening Humane Quality [J]. Secondary vocational education. 2009, (10). 